\author{
Marquette University \\ e-Publications@Marquette
}

$5-1-2019$

\title{
The Role of Neurocognitive Tests in the Assessment of Adult Attention-Deficit/Hyperactivity Disorder
}

Molly A. Nikolas

University of lowa

Paul S. Marshall

Hennepin County Medical Center

James B. Hoelzle

Marquette University, james.hoelzle@marquette.edu

Follow this and additional works at: https://epublications.marquette.edu/psych_fac

Part of the Psychology Commons

\section{Recommended Citation}

Nikolas, Molly A.; Marshall, Paul S.; and Hoelzle, James B., "The Role of Neurocognitive Tests in the Assessment of Adult Attention-Deficit/Hyperactivity Disorder" (2019). Psychology Faculty Research and Publications. 425.

https://epublications.marquette.edu/psych_fac/425 
Marquette University

e-Publications@Marquette

\section{Psychology Faculty Research and Publications/College of Arts and Sciences}

This paper is NOT THE PUBLISHED VERSION; but the author's final, peer-reviewed manuscript. The published version may be accessed by following the link in the citation below.

Psychological Assessment, Vol. 31, No. 5 (2019): 685-698. DOI. This article is C American Psychological Association and permission has been granted for this version to appear in e-Publications@Marquette. American Psychological Association does not grant permission for this article to be further copied/distributed or hosted elsewhere without the express permission from American Psychological Association.

\section{The Role of Neurocognitive Tests in the Assessment of Adult Attention- Deficit/Hyperactivity Disorder}

Molly A. Nikolas

Department of Psychological and Brain Sciences, University of lowa

Paul Marshall

Department of Psychiatry, Hennepin County Medical Center, Minneapolis, Minnesota

James B. Hoelzle

Department of Psychology, Marquette University

\section{Acknowledgement}

This research was supported by Shire Pharmaceutical (Grant USA-000594 to Paul Marshall and Molly A. Nikolas) and the Minnesota Medical Foundation. 


\section{Abstract}

Despite widespread recognition that attention-deficit/hyperactivity disorder (ADHD) is a lifelong neurodevelopmental disorder, optimal methods of diagnosis among adults remain elusive. Substantial overlap between ADHD symptoms and cognitive symptoms of other mental health conditions, such as depression and anxiety, and concerns about validity in symptom reporting have made the use of neuropsychological tests in ADHD diagnostic assessment appealing. However, past work exploring the potential diagnostic utility of neuropsychological tests among adults has often relied on a relatively small subset of tests, has failed to include symptom and performance validity measures, and often does not include comparison groups of participants with commonly comorbid disorders, such as depression. The current study examined the utility of an extensive neuropsychological measure battery for diagnosing ADHD among adults. Two hundred forty-six participants (109 ADHD, 52 depressed, 85 nondisordered controls) completed a multistage screening and assessment process, which included a clinical interview, self, and informant report on behavior rating scales, performance and symptom validity measures, and an extensive neuropsychological testing battery. Results indicated that measures of working memory, sustained attention, response speed, and variability best discriminated ADHD and non-ADHD participants. While single test measures provided performed poorly in identifying ADHD participants, analyses revealed that a combined approach using self and informant symptom ratings, positive family history of $A D H D$, and a reaction time (RT) variability measure correctly classified $87 \%$ of cases. Findings suggest that neuropsychological test measures used in conjunction with other clinical assessments may enhance prediction of adult ADHD diagnoses.

\section{Public Significance Statement}

Public Significance Statement: This study suggests that cognitive tests may be most useful in the diagnostic assessment of ADHD among adults when used in combination with symptom report scales and family history information. These results caution against the use of cognitive tests alone in the diagnostic process and emphasize inclusion of performance validity measures and measures of depression when evaluating ADHD among adults.

\section{Keywords}

attention-deficit/hyperactivity disorder, diagnostic assessment, neuropsychological tests

\section{Introduction}

Once considered a disorder of childhood, it is now widely recognized that attention-deficit/hyperactivity disorder (ADHD) is a lifelong neurodevelopmental syndrome (Kessler et al., 2005). Recent national surveys have estimated prevalence of ADHD as high as 11\% among youth (Visser et al., 2014), however, prevalence estimates are somewhat lower among adults, ranging between $2 \%$ to $6 \%$, depending on the criteria used (Barkley, Murphy, \& Fischer, 2008; Vitola et al., 2017). These prevalence estimates have increased over the past decade, leading to growing concerns that ADHD may be overdiagnosed, particularly among adults (Hinshaw \& Sheffler, 2014; Paris, Bhat, \& Thombs, 2015). Supporting this concern, prescriptions for ADHD medications for patients between the ages of 20 and 39 have substantially increased in the past 10 years (Johansen, Matic, \& McAlearney, 2015; Renoux, Shin, Dell'Aniello, Fergusson, \& Suissa, 2016), with estimates suggesting anywhere between a 280 and $800 \%$ increase in stimulant medication prescriptions for adults since the early 2000 s.

Determining the optimal diagnostic assessment procedures for ADHD among adults remains a critical component to the continued study of its phenomenology, correlates, developmental course, and treatment. However, multiple challenges remain in the assessment of adult ADHD, both for research and clinical purposes. First, many young adults, especially college students, experience occasional ADHD symptoms, particularly inattention-disorganization (Drake, Riccio, \& Hale, 2017; DuPaul, Weyandt, O'Dell, \& Varejao, 2009). Thus, it may be difficult for general medical professionals without specialized training in ADHD to differentiate between 
those with sufficient symptoms and impairment to warrant a diagnosis from those with occasional or situational difficulties (Epstein et al., 2014). This problem is also compounded by the fact that attention and concentration difficulties are nearly identical in description to cognitive symptoms of depression and anxiety and are often associated with similar cognitive deficits (Prevatt, Dehili, Taylor, \& Marshall, 2015; Spencer, Biederman, \& Mick, 2007). Second, there may be secondary gains associated with endorsement of ADHD symptoms (particularly in college settings) including access to academic/work-related accommodations as well as stimulant medications (Advokat, Lane, \& Luo, 2011; Arria et al., 2008). Inclusion of performance validity tests (PVTs) and symptom validity tests (SVTs) have been successful in identifying invalid symptom presentation among adults presenting for an evaluation of ADHD (Marshall, Hoelzle, Heyerdahl, \& Nelson, 2016; Musso \& Gouvier, 2014). However, it remains unclear how often issues of invalid symptom presentation are considered when evaluating the disorder in adults. Recent expert recommendations regarding the optimal means of assessing adult ADHD have pointed out the importance of including such validity measures (Ramsey, 2015).

Third, only the most recent revision to the Diagnostic and Statistical Manual of Mental Disorders (5th ed.; DSM5; American Psychiatric Association, 2013) has specified adult-specific symptom wording and thresholds within the ADHD diagnostic criteria. Thus, application of adult-specific criteria may be unfamiliar to those making the diagnosis. The need for adult-specific symptom criteria and diagnostic thresholds caused significant debate during the DSM revision process (Bell, 2011) and continues to be contested in the literature (Matte et al., 2015; Sibley, Coxe, \& Molina, 2017; Vitola et al., 2017). The current criteria rely on reports of current symptoms as well as retrospective reports of childhood behavior prior to Age 12. The accuracy of retrospective self-reports of childhood behavior remains somewhat questionable (Mannuzza, Klein, Klein, Bessler, \& Shrout, 2002). However, prior work has demonstrated that specifying presence of symptoms before Age 12 (compared with Age 7 in $D S M-I V$ ) likely improved reliability of retrospective reports of symptoms while not substantially increasing the prevalence of adult ADHD (Kieling et al., 2010). Notably, the accuracy of diagnostic assessment of ADHD may be improved by including reports of symptoms from informants, such as parents (Dvorsky, Langberg, Molitor, \& Bourchtein, 2016; Sibley et al., 2017) as well as considering family history of ADHD (Kooij et al., 2010), given work indicating significant heritability of ADHD (Nikolas \& Burt, 2010). However, few studies have explicitly examined the extent to which inclusion of such information enhances diagnostic prediction.

In general, an unstructured clinical interview combined with self-reports on behavioral rating scales of ADHD symptoms remain the most common tools used in diagnosing ADHD among adults (Dvorsky et al., 2016; Nelson, Whipple, Lindstrom, \& Foels, 2014). Using neuropsychological testing has been proposed as one strategy to improve the accuracy of diagnostic assessment, given the range of cognitive deficits associated with ADHD in adulthood (Mostert et al., 2015; Weyandt, Oster, Gudmundsdottir, DuPaul, \& Anastopoulos, 2017) as well as the continuation of neurocognitive problems into adulthood among those with ADHD (van Lieshout, Luman, Buitelaar, Rommelse, \& Oosterlaan, 2013). Some past work has shown that inclusion of tests of executive functioning, particularly working memory and inhibition, as well as tests of sustained attention have improved diagnostic accuracy of ADHD assessment (Grodzinsky \& Barkley, 1999; Lovejoy et al., 1999). More recently, machine learning paradigms have also been able to utilize neuropsychological data to accurately predict ADHD diagnoses among children (Bledsoe et al., 2016). However, other studies have also shown limited utility of these neuropsychological tests in improving diagnostic accuracy (Barkley et al., 2008; Rapport, Van Voorhis, Tzelepis, \& Friedman, 2001). Notably, single neuropsychological tests have been found to poorly discriminate between youth with and without ADHD (Doyle, Biederman, Seidman, Weber, \& Faraone, 2000) and normal performance on any given test has been shown to poorly predict the absence of ADHD (Perugini, Harvey, Lovejoy, Sandstrom, \& Webb, 2000). This is likely due to the substantial heterogeneity in neuropsychological performance among those with and without ADHD (Fair, Bathula, Nikolas, \& Nigg, 2012).

While there is some indication that combined approaches (i.e., interview, behavior rating scale, and neuropsychological testing) may provide improved diagnostic accuracy (Perugini et al., 2000), past work exploring these questions has been limited in several ways. First, many studies have focused on a few 
neuropsychological domains and have not incorporated other tests commonly used in clinical neuropsychological practice, which may potentially be more sensitive in identifying ADHD-related cognitive deficits. Second, nearly all this work has failed to incorporate PVTs to ensure valid effort. Third, only one study of the diagnostic accuracy of a combined approach (including PVTs) has been done with adults, a group for which diagnosis remains particularly challenging. Many of these studies have failed to consider how measures might distinguish ADHD from those with other disorders, such as depression, that present with similar concentration and attention problems. Distinguishing between adult ADHD and depression is of particular importance, given the high rates of comorbidity between ADHD and depression in adults (Kessler et al., 2006) as well the common patterns of cognitive deficits associated with each condition (Prevatt et al., 2015; Spencer et al., 2007). Few prior studies have evaluated the degree to which each source of information (i.e., rating scales, test scores) improves diagnostic accuracy as well as how various cut scores available across many commonly used measures may impact their diagnostic utility.

Therefore, the purpose of the current study was to examine performance across a large and diverse neuropsychological measure battery among adults with ADHD, adults with unipolar depression, and controls with the goal of determining if inclusion of such measures improved diagnostic accuracy of ADHD. Here, we also examined behavior rating scales from participants and informants that assessed current and childhood symptoms as well as current ADHD-related functional impairments, along with neuropsychological test performance to determine which combination of these measures resulted in the highest diagnostic accuracy of ADHD among adults. Based on prior work, we predicted that inclusion of tests of neuropsychological functioning, particularly sustained attention, would improve diagnostic accuracy for adult ADHD.

\section{Method}

\section{Participants}

Participants were 256 adults Ages $18-40$ years (Mage $=23.9$ years, $S D=5.1$ years, $60.6 \%$ female, $83.7 \%$ Caucasian). Adult volunteers were recruited via advertisements, e-mail listservs, and outreach to local neuropsychological clinics to obtain as representative a sample as possible while avoiding the inherent biases associated with relying on a purely clinic-referred sample. Study participants were recruited across two sites into one of three potential groups: adults with a diagnosis of ADHD, adults with a diagnosis of unipolar mood disorder (depressed), and adults with neither diagnosis (controls, see the Testing Procedures section). Enrollment in the study also required all participants to give contact information for an informant, who could provide reports regarding their current and childhood ADHD symptoms. Demographic characteristics (i.e., age, sex, ethnicity, household income) did not vary by recruitment location (all $p s>.22$ ).

A multistage process was used to identify cases and noncases among those who volunteered (see Figure 1). Interested participants first completed an eligibility screening process conducted by bachelor's and master's level research project staff at Stage 1 to evaluate inclusion and exclusion criteria. Participants were excluded if they (a) were not fluent in English; (b) had any physical illness or neurological conditions, including a history of head injuries, which might compromise central nervous system and cognitive functioning; (c) had a history of major psychiatric disorder other than depression or anxiety disorders; (d) had ever been diagnosed with a learning disability, (5) had a history of preterm birth (birth prior to 33 weeks gestation); or (e) had significant alcohol, illicit drug, or prescription drug abuse (based on the frequency, number of years of use, and total amount used per week), that were considered capable of causing impaired cognitive testing performance. While prior work has been somewhat inconsistent in including/excluding individuals with comorbid neurodevelopmental problems, including learning disorders, we elected to take a conservative approach and exclude those with other neurodevelopmental conditions to ensure that any cognitive deficits we observed were due to ADHD and not a combination of different problems. Additionally, participants were excluded if they were taking long-acting stimulant medications $(n=77)$ or were not willing to complete a wash out of stimulant 
medication prior to testing $(n=12)$. A total of 882 participants completed the initial screening process, of which 282 were excluded.

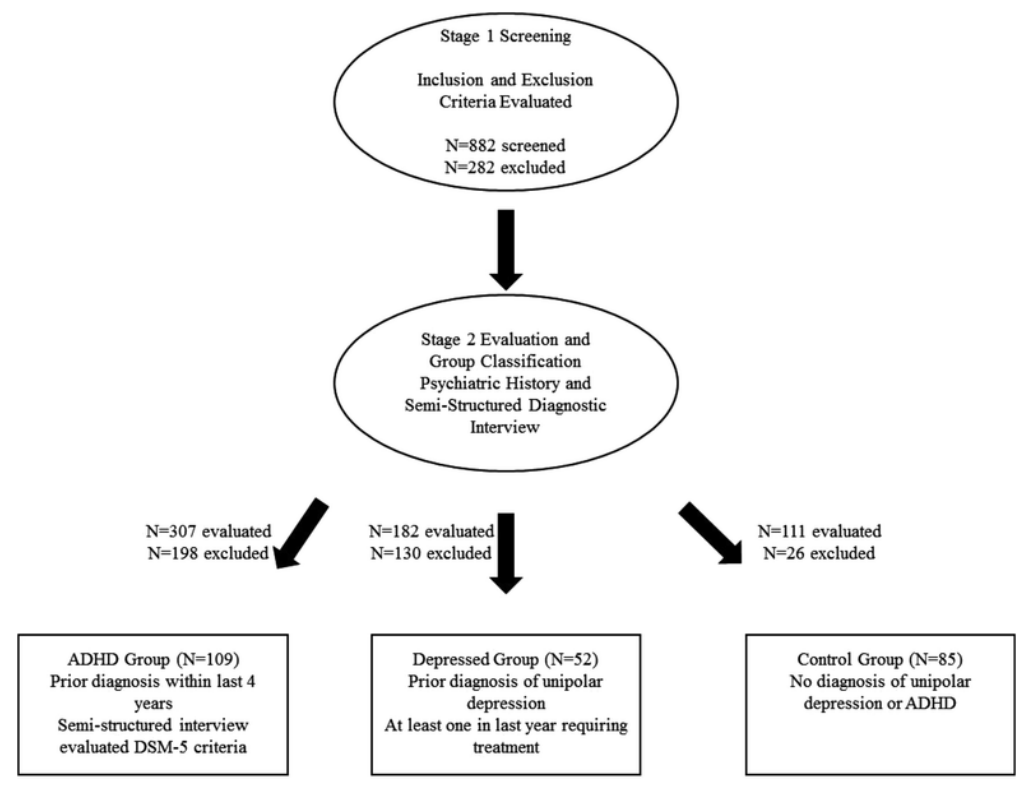

Figure 1. Multistage recruitment procedure.

Following the initial screening process, the remaining 600 eligible participants completed the Stage 2 screening to determine diagnostic grouping. To be considered for the ADHD group, participants had to endorse having a prior diagnosis based upon a comprehensive clinical interview and standardized assessment of psychiatric status (i.e., behavioral rating scales) as well as onset of symptoms and impairment prior to Age 16. Any prior diagnosis had to have been made during the preceding 4 years. Participants had to meet full $D S M-5$ diagnostic criteria to be retained in the ADHD group. To determine final inclusion in the ADHD group, potential ADHD participants completed a semistructured interview of adult ADHD symptoms based on Kessler et al. (2010) to ensure that current and childhood symptoms were above DSM-IV/DSM-5 diagnostic thresholds. These thresholds include $6+$ symptoms present during childhood prior to Age 12 and 5+ symptoms present within the past 6 months. A total of 307 potential ADHD participants completed the Stage 2 screening, and 109 were deemed eligible and enrolled in the study.

To be included in the depressed group, participants had to endorse receiving a diagnosis of a unipolar mood disorder from a mental health professional based upon a comprehensive clinical interview and standardized assessment of psychiatric status. Additionally, participants had to endorse having at least one mood episode during the past year that required either medication or behavioral treatment. We set these criteria in order to try to closely compare cognitive performance of individuals with ADHD and those with recent, active symptoms of depression. A total of 182 potential depressed group participants completed the Stage 2 screening, and 52 were deemed eligible and enrolled in the study.

Lastly, (out of the 111 screened) 85 community volunteers presenting with no history of either ADHD or unipolar mood disorder were enrolled in the study as controls. While a formal matching process was not implemented, control participants were enrolled to approximately correspond to the clinical groups based on age and sex. Screening procedures resulted in a total sample of 246 participants (109 ADHD, 52 depressed, and 85 controls). All participants completed a standardized neuropsychological testing battery and questionnaire measures, as follows. Additionally, all participants were compensated for their time and parking expenses were paid. All procedures were approved by the local institutional boards. 


\section{Testing Procedures}

Each participant completed a comprehensive neuropsychological evaluation, consistent with recommendations for a multimethod assessment of adult ADHD (Frazier, Demaree, \& Youngstrom, 2004; Weyandt et al., 2013). The testing procedures included multiple cognitive tests, behavioral observations, self and informant ADHD behavior rating scales, ratings of depression and anxiety symptoms, PVTs, and an SVT. All participants taking stimulant medication completed a 24- or 48-hr wash-out procedure, depending on whether the medicine was short or long acting ( $M$ wash-out time $=37.4 \mathrm{hr}, S D=14.6$ ). The cognitive tests were administered according to standardized instructions by trained and supervised clinical psychology doctoral students and advanced undergraduate students. The tests were administered in the same order for all participants (Marshall et al., 2016). Tests were selected based on review of three meta-analyses of neuropsychological performance among adults with ADHD (Alderson, Kasper, Hudec, \& Patros, 2013; Boonstra, Oosterlaan, Sergeant, \& Buitelaar, 2005; Hervey, Epstein, \& Curry, 2004) and were included to cover several broad domains, including executive functioning (e.g., working memory, inhibition, set-shifting, interference control, planning), memory, processing speed, and sustained attention/vigilance. Included tests had a conceptual and empirical association with ADHD and the battery was selected to adequately cover verbal, visual, and motor processing domains.

Participants completed the Vocabulary, Block Design, Digit Span, and Symbol Search subtests of the Wechsler Adult Intelligence Scale (4th ed.; Wechsler, 2008a); the California Verbal Learning Test-II (CLVT-II; Delis, Kramer, Kaplan, \& Ober, 2000); the Verbal Fluency, Design Fluency, Color-Word Interference Test (CWIT), and Tower test from the Delis-Kaplan Executive Function System (DKEFS; Delis, Kaplan, \& Kramer, 2001); the Neuropsychological Assessment Battery (NAB) Numbers and Letters Test (White \& Stern, 2003); the Word Memory Test (WMT; Green, 2003); the Paced Auditory Serial Addition Test (PASAT-100; Diehr et al., 2003); the Salthouse Listening Span Test (Salthouse, 1994); the Test of Variables of Attention (TOVA; Greenberg, Kindschi, Dupuy, \& Corman, 1996); the Dot Counting Test (Boone, Lu, \& Herzberg, 2002b); the Sentence Repetition Test (Strauss, Sherman, \& Spreen, 2006); the Spatial Addition subtest of the Wechsler Memory Scales (4th ed.; Wechsler, 2008b), and the b-Test (Boone, Lu, \& Herzberg, 2002a). PVT measures were interspersed throughout the testing battery, given that effort can fluctuate significantly throughout a testing session (Boone, 2009). The following PVT cutoff scores were used to identify suspect effort per Marshall et al. (2016): a score of 6 or less on the Reliable Digit Span score (Babikian, Boone, Lu, \& Arnold, 2006), two or more errors on the Forced Choice Recognition Test of the CVLT-II (Root, Robbins, Chang, \& Van Gorp, 2006), a Sentence Repetition score of 10 or less (Schroeder \& Marshall, 2010), and less than 82.5\% correct for the immediate recognition, delay recognition, or recall consistency scores on the WMT (Green, 2003). Further, an e-score of 14 or greater on the Dot Counting Test, e score of 70 or more on the b-Test, and response variability values of greater than $180 \mathrm{~ms}, 26$ or more omission errors, and 31 or more commission errors on the TOVA were used to identify suspect effort.

Following the completion of the testing battery, participants completed several normed behavior rating scales to assess ADHD, depression, and anxiety symptomatology. Both participants and their informants completed the current and childhood symptom versions of the Barkley Adult ADHD Rating Scale (BAARS-IV, Barkley, 2011a), the Barkley Deficits in Executive Function Scale-Short Form (BDEFS-SF; Barkley, 2011b), and the Barkley Functional Impairment Scale (BFIS, Barkley, 2011c). The BAARS-IV requires respondents to rate the frequency of all 18 DSM-IV ADHD symptoms on a 4-point Likert scale (never/rarely, sometimes, often, and very often). Additionally, both participants and their informants completed the BDEFS-SF (Barkley, 2011b). The BDEFS requires respondents to report the frequency of various executive function-related problems on a 4-point Likert scale (never/rarely, sometimes, often, and very often), including difficulties with time management, organization, restraint, motivation, and emotion regulation. Participants and their informants also completed the BFIS (Barkley, 2011c). The BFIS requires respondents to report the degree to which they believe their ADHD symptoms are impairing their functioning across multiple domains (e.g., in completing tasks at home, in their interpersonal relationships, in their work/school activities). Lastly, participants also completed the Beck Depression Inventory-II (Beck, Steer, \& Brown, 1996), a 21-item scale examining the severity of depression symptoms as well as the 21-item Beck Anxiety Inventory (Beck \& Steer, 1993), which quantifies the severity of 
anxiety symptoms. Finally, both participants and informants also completed the Clinical Assessment of Attention Deficit-Adult Infrequency scale (Bracken \& Boatwright, 2005) which is an SVT. The endorsement of three or more of the 10 items on this scale was considered to be indicative of symptom exaggeration or embellishment (Marshall et al., 2016).

\section{Data Analytic Strategy}

Descriptive statistics for the diagnostic measures were first calculated by group (ADHD, depressed, and control) and differences evaluated via analysis of variance. To facilitate interpretation of results, all neuropsychological test scores were transformed to reduce skewness and mean centered, such that higher scores reflected worse performance. Normed values were used for each measure to manage differences related to age and sex. Participants who were below thresholds on two or more PVT/SVTs were determined to have made an invalid symptom presentation ( $n=6$, all in the ADHD group), based on prior work (Marshall et al., 2016).

Prior to conducting the primary analyses, the diagnostic accuracy of each neuropsychological test measure was preliminarily assessed via calculation of the area under the curve (AUC) via a series of receiver operator characteristic (ROC) analyses. These analyses examined the utility of each measure in distinguishing each dyadic grouping (i.e., ADHD vs. non-ADHD, ADHD vs. control, and ADHD vs. depressed). Measures with AUC values significantly greater than .50 (which represents the probability that a test score will rank a randomly chosen case higher than a randomly chosen noncase) were retained for the primary analyses.

Regression analyses were then conducted to evaluate our primary questions regarding the utility of neuropsychological test measures for distinguishing adult ADHD. Specifically, a series of stepwise binary logistic regression analyses as well as a multinomial logistic regression were conducted to determine which measures best distinguished participants with ADHD from those without ADHD (including controls and patients with depression). In these models, all neuropsychological test measures were included as predictors and an iterative process was used to determine the best fitting model. Standardized, mean-centered scores were used as the predictors (all skewness <.70) and estimated full-scale IQ and stimulant medication status were included as covariates. Outcomes included binary diagnostic groupings (i.e., ADHD vs. non-ADHD, ADHD vs. control, ADHD vs. depressed) and the three-group multinomial comparison (i.e., ADHD vs. control vs. depressed). Model fit was evaluated using the omnibus chi-square as well as the Hosmer and Lemeshow chi-square statistics. In addition to models predicting diagnostic group, additional analyses also examined test measures as predictors of dimensional scores of ADHD symptom severity and impairment (mean of self- and informant ratings) using a stepwise linear regression framework. Neuropsychological test measures that were found to significantly and incrementally contribute to the prediction of group membership and/or the variance in symptom severity were then retained for a subset of further analyses.

Next, we utilized a series of procedures to determine the best method for combining rating scale and test data for predicting diagnostic grouping. First, specific cut scores that optimized sensitivity, specificity, positive predictive power, and negative predictive power were determined for a final subset of neuropsychological test measures based on the prior analyses. We retained measures that were found to: (a) have marginal or better (>.60) AUC values, and (b) significantly and incrementally contribute to the prediction of diagnostic group and/or symptom severity variance. From here, we utilized a series of stepwise binary logistic regression analyses to determine the degree to which each of the following indicators improved prediction of ADHD diagnoses: (a) selfreports of current symptoms and impairment, (b) self-report of childhood symptoms, (c) informant reports of current symptoms, (d) family history of ADHD diagnosis, and (e) our subset of best-performing neuropsychological test cut scores. 


\section{Results}

\section{Descriptive Statistics}

Demographic and descriptive statistics for the sample are presented in Table 1. As seen there, our recruitment and diagnostic assessment procedures were effective in distinguishing our groups. As expected, adults in the ADHD group had significantly higher levels of inattention and hyperactivity-impulsivity symptoms, both currently and during childhood. They were significantly more likely to be taking stimulant medication than those in the depressed or nondisordered control groups. Notably, adults in the depressed group had significantly higher scores on the BDI than the ADHD and control groups. While adults in the depressed group reported higher levels of ADHD symptoms compared with controls, these did not reach clinical diagnostic thresholds. As expected, there was a higher proportion of males in the ADHD group relative to the depressed and control groups. Importantly, however, the three groups did not differ in regard to age, ethnicity, and years of education. Notably, average IQ and education were generally above average relative to population norms.

Table 1. Demographic and Descriptive Statistics for ADHD and Non-ADHD Control and Depressed Participants

\begin{tabular}{|c|c|c|c|c|c|}
\hline Sample characteristic & Control & ADHD & Depressed & $p$ value & Diff \\
\hline$N$ & 85 & 109 & 52 & & \\
\hline Male (\%) & 32.9 & 49.5 & 28.8 & .01 & $A, C>D$ \\
\hline Caucasian (\%) & 80.0 & 85.3 & 86.5 & .29 & \\
\hline Age & $22.9(4.5)$ & $24.8(6.2)$ & $23.6(5.4)$ & .06 & \\
\hline Education (years) & $14.9(1.9)$ & $15.4(2.5)$ & $15.0(2.2)$ & .24 & \\
\hline Stimulant medication (\%) & 0 & 76.1 & 0 & $<.001$ & $A>D, C$ \\
\hline Current inattention symptoms & $.62(1.4)$ & $5.1(2.8)$ & $2.4(2.8)$ & $<.001$ & $A>D>C$ \\
\hline Current hyperactive-impulsive symptoms & $.95(1.5)$ & $3.9(2.4)$ & $1.9(2.3)$ & $<.001$ & $A>D>C$ \\
\hline Childhood inattention symptoms & $1.0(2.0)$ & $5.5(3.1)$ & $1.8(2.6)$ & $<.001$ & $A>D, C$ \\
\hline Childhood hyperactive-impulsive symptoms & $1.3(1.9)$ & $4.6(3.1)$ & $1.9(2.4)$ & $<.001$ & $A>D, C$ \\
\hline BDEFS percentile score & $56.0(21.4)$ & $84.7(15.9)$ & $78.9(19.4)$ & $<.001$ & $A, D>C$ \\
\hline BFIS percentile score & $58.6(12.9)$ & $77.1(15.0)$ & $74.0(16.6)$ & $<.001$ & $A, D>C$ \\
\hline Informant inattention symptoms & $.43(1.1)$ & $4.0(2.7)$ & $1.9(2.3)$ & $<.001$ & $A>D>C$ \\
\hline Information hyperactive-impulsive symptoms & $.58(1.4)$ & $3.3(2.7)$ & $1.2(1.8)$ & $<.001$ & $A>D, C$ \\
\hline Beck Depression Inventory score & $5.0(5.1)$ & $10.5(8.2)$ & $16.0(10.9)$ & $<.001$ & $D>A>C$ \\
\hline Beck Anxiety Inventory score & $2.8(5.1)$ & $8.5(8.8)$ & $9.4(9.1)$ & $<.001$ & $D, A>C$ \\
\hline
\end{tabular}

Note. $p$ value indicates significant difference at level of three groups. Stimulant medication indicates proportion of participants taking stimulant medication at time of assessment (and how underwent washout procedure). Values in parentheses are standard deviations. Diff _ pattern of post hoc group differences; BDEFS _ Barkley Deficits in Executive Function Scale; BFIS = Barkley Functional Impairment Scale; $A=$ attentiondeficit/hyperactivity disorder (ADHD); D = depressed, $C=$ control.

\section{Neuropsychological Test Measures}

ROC analyses indicated that several test measures were marginal or better predictors of diagnostic group membership (Table 2). These analyses were first conducted examining measures distinguishing ADHD versus all non-ADHD participants (depressed and control patients both) followed by analyses distinguishing ADHD versus control and ADHD versus depressed group membership. Notably these analyses produced completely overlapping results and identified several test measures for inclusion in subsequent regression analyses. These measures included: CVLT short delay free recall, all three indices from the Salthouse Listening Span Test, DKEFS Letter Fluency, DKEFS CWIT inhibition/switching, DKEFS Design Fluency test filled and empty dots, and the reaction time (RT) variability, $\mathrm{RT}$, omission errors, and $d$-prime score from the TOVA, and the speed score from the NAB Numbers and Letters test. 
Table 2. Receiver Operating Characteristic Analyses for Neurocognitive Test Measures: ADHD Versus Non-ADHD

\begin{tabular}{|c|c|c|c|}
\hline Neurocognitive measures & AUC & $p$ value & $95 \% \mathrm{Cl}$ \\
\hline CVLT Trial 1 & .51 & .91 & {$[.43, .58]$} \\
\hline CVLT Trial 5 & .55 & .17 & {$[.48, .63]$} \\
\hline CVLT short delay free recall & .59 & .01 & {$[.52, .66]^{a, b}$} \\
\hline CVLT long delay free recall & .56 & .12 & {$[.48, .64]$} \\
\hline CVLT recognition & .51 & .81 & {$[.43, .58]$} \\
\hline Listening Span trials & .63 & $<.001$ & {$[.56, .70]^{a, b}$} \\
\hline Listening Span items & .61 & .003 & {$[.54, .68]^{a, b}$} \\
\hline Listening Span score & .62 & .001 & {$[.55, .69]^{\mathrm{a}}$} \\
\hline Sentence repetition & .55 & .18 & {$[.48, .62]$} \\
\hline WMS Spatial Addition & .53 & .37 & {$[.46, .61]$} \\
\hline Letter fluency & .58 & .03 & {$[.51, .65]^{\mathrm{a}}$} \\
\hline Color naming & .52 & .53 & {$[.45, .60]$} \\
\hline Word reading & .55 & .22 & {$[.47, .62]$} \\
\hline Inhibition & .53 & .44 & {$[.46, .60]$} \\
\hline Inhibition/switching & .60 & .009 & {$[.53, .67]^{a, b}$} \\
\hline Design Fluency filled & .59 & .02 & {$[.51, .66]^{a}$} \\
\hline Design Fluency empty & .58 & .03 & {$[.51, .66]^{a}$} \\
\hline Design Fluency switching & .55 & .16 & {$[.48, .63]$} \\
\hline Tower & .56 & .12 & {$[.49, .63]$} \\
\hline PASAT & .49 & .73 & {$[41, .55]$} \\
\hline TOVA reaction time variability & .66 & $<.001$ & {$[.59, .74]^{a, b}$} \\
\hline TOVA reaction time & .65 & $<.001$ & {$[.58, .72]^{a, b}$} \\
\hline TOVA commission errors & .56 & .15 & {$[.48, .63]$} \\
\hline TOVA omission errors & .66 & $<.001$ & {$[.59, .73]^{\mathrm{a}, \mathrm{b}}$} \\
\hline TOVA d-prime & .64 & $<.001$ & {$[.57, .72]^{a, b}$} \\
\hline Numbers and letters speed & .59 & .04 & {$[.51, .67]^{a}$} \\
\hline Numbers and letters efficiency & .43 & .07 & {$[.36, .50]$} \\
\hline
\end{tabular}

Note. Bolded measures had AUC scores significantly greater than .50. ADHD = attention-deficit/hyperactivity disorder; $A U C=$ area under the curve; CVLT = California Verbal Learning Test; WMS = Wechsler Memory Scales; PASAT $=$ Paced Auditory Serial Addition Test; TOVA = Test of Variables of Attention .

${ }^{a}$ Scores indicate significant AUC in analyses examining ADHD versus controls.

${ }^{b}$ Scores with indicate significant AUC in analyses examining ADHD versus depressed.

\section{Predicting Diagnostic Group Membership}

\section{ADHD versus non-ADHD}

Stepwise binary logistic regression analyses were first used to examine these test measures as predictors of group status (ADHD vs. non-ADHD, including both individuals in the depressed and the control groups; $\underline{\text { Table } 3}$ ). Findings indicated that the best-fitting model included five significant test measures as predictors of ADHD diagnostic status and improved model fit compared with the intercept-only model (omnibus $\chi^{2}=44.7, p<.001$; Hosmer and Lemeshow $\chi^{2}=11.2, p=.19$; Nagelkerke $R^{2}=.23$ ). Examination of parameters indicated that worse performance (indexed by higher scores) on CVLT short-delay free recall $(\beta=.33, p=.029$, odds ratio $(O R)=1.4$, $95 \% \mathrm{Cl}[1.03,1.9])$, Salthouse Listening Span trials $(\beta=.35, p=.021, O R=1.4,95 \% \mathrm{Cl}[1.1,1.9])$, DKEFS CWIT inhibition/switching $(\beta=.37, p=.012, O R=1.5,95 \% \mathrm{Cl}[1.1,1.9])$, TOVA RT variability $(\beta=.36, p=.030, O R=1.4$, $95 \% \mathrm{Cl}[1.0,2.0])$, and TOVA omission errors $(\beta=.43, p=.01, O R=1.5,95 \%[\mathrm{Cl} 1.1,2.1])$ all significantly and 
incrementally predicted membership in the ADHD group compared with the non-ADHD group, with an overall classification accuracy of $72.1 \%$.

Table 3. Neurocognitive Test Measures as Predictors of ADHD Diagnostic Groupings: Stepwise Logistic Regression Analyses

\begin{tabular}{|l|l|l|l|l|}
\hline Measure & $\boldsymbol{\beta}$ & $\boldsymbol{p}$ value & $\boldsymbol{O R}$ & $\mathbf{C l}$ \\
\hline ADHD vs. non-ADHD & & & & \\
\hline CVLT short delay & .33 & .029 & 1.4 & {$[1.03,1.9]$} \\
\hline Listening span & .35 & .021 & 1.4 & {$[1.1,1.9]$} \\
\hline CW inhibition/switching & .37 & .012 & 1.5 & {$[1.1,1.9]$} \\
\hline TOVA reaction time variability & .36 & .030 & 1.4 & {$[1.1,2.0]$} \\
\hline TOVA omission errors & .43 & .010 & 1.5 & {$[1.1,2.1]$} \\
\hline ADHD vs. control & & & & \\
\hline Listening Span & .45 & .008 & 1.6 & {$[1.1,2.2]$} \\
\hline TOVA omission errors & .73 & $<.001$ & 2.1 & {$[1.5,3.0]$} \\
\hline ADHD vs. depressed & & & & \\
\hline CVLT short delay & .37 & .039 & 1.4 & {$[1.0,2.1]$} \\
\hline TOVA reaction time & .48 & .008 & 1.6 & {$[1.1,2.3]$} \\
\hline Three-group multinomial & & & & \\
\hline Listening Span & .46 & .006 & 1.6 & {$[1.1,2.2]$} \\
\hline TOVA omission errors & .72 & $<.001$ & 2.1 & {$[1.5,3.0]$} \\
\hline
\end{tabular}

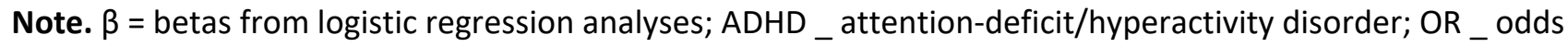
ratio; $\mathrm{Cl}_{-}$95\% confidence interval for odds ratio; CVLT California Verbal Learning Test; CW = Color-Word; TOVA _ Test of Variables of Attention.

\section{ADHD versus control}

A second stepwise binary logistic regression analyses was conducted to determine which neuropsychological test measures best distinguished participants with ADHD from nondisordered controls. Here, findings indicated that the best-fitting model included two predictors and improved model fit relative to the intercept-only model (omnibus $\chi^{2}=30.1, p<.001$; Hosmer and Lemeshow $\chi^{2}=6.4, p=.61$; Nagelkerke $R^{2}=.20$ ). In this model, worse performance on both Salthouse Listening Span trials $(\beta=.45, p=.008, O R=1.6,95 \% \mathrm{Cl}[1.1,2.2])$ and TOVA omission errors $(\beta=.73, p<.001, O R=2.1,95 \% \mathrm{Cl}[1.5,3.0])$ significantly predicted membership in the ADHD group compared with nondisordered controls, with a classification accuracy of $68.3 \%$.

\section{ADHD versus depressed}

A third stepwise binary logistic regression analysis was used to determine which test measures best distinguished ADHD participants from those with the depression. Again, two test measures emerged as predictors in the best-fitting model, which exhibited improved fit relative to the intercept-only model (omnibus $\chi^{2}=12.8, p=.002$; Hosmer and Lemeshow $\chi^{2}=7.7, p=.47$; Nagelkerke $R^{2}=.11$ ). Worse performance on the CVLT short-delay free recall $(\beta=.37, p=.039, O R=1.4,95 \% \mathrm{Cl}[1.0,2.1])$ and TOVA RT $(\beta=.48, p=.008, O R=$ $1.6,95 \% \mathrm{Cl}[1.1,2.3])$ were associated with membership in the ADHD group relative to the depressed group, with a classification accuracy of $70.4 \%$.

\section{Multinomial logistic regression}

Similarly, a stepwise multinomial logistic regression analysis was conducted to determine which neuropsychological test measures distinguished best among all three groups. The iterative procedure again revealed two measures best distinguished the three groups and improved model fit relative the intercept-only model (omnibus $\chi^{2}=34.3, p<.001$; Hosmer and Lemeshow $\chi^{2}=16.3, p=.46$; Nagelkerke $R^{2}=.15$ ). Again, worse 
performance on both the Salthouse Listening Span trials $(\beta=.46, p=.006, O R=1.6,95 \% \mathrm{Cl}[1.1,2.2])$ and TOVA omission errors $(\beta=.72, p<.001, O R=2.1,95 \% \mathrm{Cl}[1.5,3.0])$ significantly predicted membership in the ADHD group compared with nondisordered controls. However, neither measure distinguished depressed patients from controls (all ps > .26).

\section{Predicting Symptom Severity and Impairment}

Stepwise linear regression analyses were then conducted to determine which test measures best predicted dimensional scores of inattention, hyperactivity-impulsivity, and functional impairment (Table 4). All models included current stimulant medication usage and estimated full-scale IQ as covariates. Two measures (TOVA RT variability, DKEFS CWIT inhibition/switching) each contributed incrementally to predicting inattention and together combined to predict $8 \%$ of the variance in these symptom severity scores. By contrast, TOVA omission errors and Salthouse Listening Span trials each uniquely predicted hyperactivity-impulsivity and accounted for $6 \%$ of the variance. TOVA RT variability and CVLT short delay free recall each predicted scores on the BDEFS-SF and together accounted for $8 \%$ of the variance. TOVA RT and Salthouse Listening Span trials both predicted functional impairment due to ADHD symptoms as reported on the BFIS and accounted for $6 \%$ of the variance. Thus, it appears that variability in neurocognitive functioning, specifically, in sustained attention and working memory functioning accounted for unique variation in severity of symptoms and impairment.

Table 4. Neurocognitive Test Measures as Predictors of Ratings of ADHD Symptom Severity, Executive Function Deficits, and Functional Impairments: Stepwise Linear Regression Analyses

\begin{tabular}{|c|c|c|c|c|c|}
\hline Predictor & $b$ & B & $\begin{array}{l}p \\
\text { value }\end{array}$ & $95 \% \mathrm{Cl}$ & $R^{2}\left(\Delta R^{2}\right)$ \\
\hline \multicolumn{6}{|c|}{ Current inattention sum score (mean self and informant) } \\
\hline TOVA reaction time variability & .23 & .23 & $<.001$ & $\begin{array}{l}{[.21} \\
.34]\end{array}$ & \\
\hline CW inhibition/switching & .16 & .16 & $<.001$ & $\begin{array}{l}{[.06,} \\
.26]\end{array}$ & $\begin{array}{l}.35 \\
(.08)\end{array}$ \\
\hline \multicolumn{6}{|c|}{$\begin{array}{l}\text { Current hyperactivity-impulsivity sum score (mean self and } \\
\text { informant) }\end{array}$} \\
\hline TOCA omission errors & .22 & .22 & $<.001$ & $\begin{array}{l}{[.11,} \\
.33]\end{array}$ & \\
\hline Listening Span trials & .12 & .13 & .034 & $\begin{array}{l}{[.01} \\
.23]\end{array}$ & $\begin{array}{l}.21 \\
(.06)\end{array}$ \\
\hline \multicolumn{6}{|l|}{ BDEFS percentile } \\
\hline TOVA reaction time variability & .27 & .27 & $<.001$ & $\begin{array}{l}{[.10,} \\
.44]\end{array}$ & \\
\hline CVLT short delay free recall & .13 & .13 & .03 & $\begin{array}{l}{[.05,} \\
.21]\end{array}$ & $\begin{array}{l}.20 \\
(.08)\end{array}$ \\
\hline \multicolumn{6}{|l|}{ BFIS percentile } \\
\hline TOVA reaction time & .17 & .17 & .01 & $\begin{array}{l}{[.04,} \\
.30]\end{array}$ & \\
\hline Listening Span trials & .17 & .17 & .006 & $\begin{array}{l}{[.05,} \\
.29]\end{array}$ & $\begin{array}{l}.15 \\
(.06)\end{array}$ \\
\hline
\end{tabular}

Note. Total $R^{2}$ value is for full model including covariates of IQ and stimulant medication. Change in $R^{2}\left(\Delta R^{2}\right)$ represents the incremental variance explained by the neurocognitive measures. $A D H D=$ attentiondeficit/hyperactivity disorder; TOVA = Test of Variables of Attention; CW = Color-Word; CVLT = California Verbal Learning Test; BDEFS = Barkley Deficits in Executive Function Scale; BFIS = Barkley Functional Impairment Scale. 


\section{Determining Cut Scores and Individual Test Diagnostic}

Individual neuropsychological test measures

Overall, six test measures consistently emerged when predicting diagnostic group membership as well as symptom severity and ADHD-related impairments: CVLT short delay free recall, Salthouse Listening Span trials, DKEFS CWIT inhibition/switching condition, and the RT variability, RT, and omission errors indices from the TOVA. We utilized the ROC data to calculate cut scores for each measure that maximized sensitivity and specificity for each in predicting ADHD group membership. We calculated Youden's $J$ statistics for each potential cut-score (defined as sensitivity + specificity -1 ), which specify the score that can maximize both sensitivity and specificity for each measure. Results are presented in Table 5. Overall, the cut scores identified as most optimal for distinguishing ADHD and non-ADHD participants were generally within the average range compared with the established norms for each test measure, which is consistent with the above average levels of education and above average IQ of the sample.

Table 5. Optimizing Sensitivity and Specificity for Key Neurocognitive Test Predictors of ADHD Diagnosis and Symptom Severity

\begin{tabular}{|c|c|c|c|c|c|}
\hline Test measure and cut-score & Sensitivity & Specificity & CPPP & cNPP & Youden \\
\hline \multicolumn{6}{|l|}{ CVLT short delay free recall } \\
\hline$<-.75$ & .22 & .97 & 3.0 & .80 & .19 \\
\hline$<-.25$ & .43 & .77 & 1.69 & .76 & .20 \\
\hline$<.25$ & .54 & .59 & 1.32 & .78 & .13 \\
\hline$<.75$ & .67 & .40 & 1.13 & .81 & .07 \\
\hline \multicolumn{6}{|l|}{ Salthouse Listening Span trials } \\
\hline$<7$ & .25 & .88 & .73 & .48 & .13 \\
\hline$<8$ & .40 & .81 & .73 & .51 & .21 \\
\hline$<9$ & .59 & .66 & .69 & .55 & .25 \\
\hline$<10$ & .74 & .46 & .63 & .58 & .20 \\
\hline \multicolumn{6}{|l|}{ DKEFS inhibition/switching } \\
\hline$<8$ & .13 & .95 & .78 & .46 & .08 \\
\hline$<9$ & .23 & .88 & .71 & .47 & .11 \\
\hline$<10$ & .41 & .68 & .63 & .48 & .09 \\
\hline$<11$ & .55 & .54 & .61 & .48 & .09 \\
\hline \multicolumn{6}{|l|}{ TOVA reaction time } \\
\hline \multicolumn{6}{|l|}{ variability } \\
\hline$<80$ & .37 & .91 & .83 & .53 & .28 \\
\hline$<85$ & .47 & .85 & .80 & .55 & .32 \\
\hline$<95$ & .51 & .82 & .79 & .60 & .33 \\
\hline$<100$ & .66 & .68 & .73 & .61 & .34 \\
\hline$<105$ & .75 & .46 & .64 & .59 & .21 \\
\hline \multicolumn{6}{|l|}{ TOVA reaction time } \\
\hline$<100$ & .32 & .84 & .71 & .49 & .16 \\
\hline$<105$ & .40 & .79 & .71 & .51 & .19 \\
\hline$<110$ & .55 & .70 & .69 & .54 & .25 \\
\hline$<115$ & .64 & .60 & .67 & .57 & .24 \\
\hline$<120$ & .72 & .47 & .64 & .57 & .19 \\
\hline \multicolumn{6}{|l|}{ TOVA omission errors } \\
\hline$<90$ & .39 & .89 & .82 & .53 & .28 \\
\hline$<95$ & .50 & .85 & .81 & .57 & .35 \\
\hline$<100$ & .58 & .75 & .75 & .58 & .33 \\
\hline
\end{tabular}


Note. Bolded values indicate optimal cut score for each measure based on Youden statistics. Corrected positive and negative predictive power used estimated base rate of 30 percent. Scores for California Verbal Learning Test (CVLT) Short Delay Free Recall are z scores. Scores from Salthouse Listening Span Trials are raw scores. Scores from Delis-Kaplan Executive Function System (DKEFS) Inhibition/Switching are scaled scores. Scores from Test of Variables of Attention (TOVA) measures are standard scores. $\mathrm{CPPP}=$ corrected positive predictive power; $\mathrm{CNPP}=$ corrected negative predictive power.

\section{Combining rating scale and neuropsychological test measures}

We next evaluated the utility of using these cut scores in combination with rating scale information. A stepwise binary logistic regression was used to examine self-reports of current symptoms and impairment, informant reports of current symptoms and impairment, family history of ADHD, and neuropsychological test measure cut scores as predictors of ADHD diagnostic status. Each step of the model retained significant unique predictors and eliminated nonsignificant predictors (Table 6 ). Results indicated that self-reports of ADHD and depression symptoms significantly distinguished ADHD from non-ADHD participants. Addition of retrospective childhood reports as well as informant reports to the model at Steps 2 and 3 also significantly improved classification accuracy. Notably, reports of family history of ADHD diagnosis in first-degree family members also significantly improved classification accuracy, particularly for ADHD participants. Of our six neuropsychological test measures, only TOVA RT variability added incrementally to predicting group membership. However, the $O R$ was relatively larger $(O R=3.1$ ) and classification accuracy improved to $87.2 \%$ (from $85.4 \%$ ), suggesting that addition of this one neuropsychological test did improve diagnostic classification within this sample.

Table 6. Diagnostic Accuracy of Combined Approach: Self-Ratings of Current Symptoms, Childhood Symptoms, Informant Ratings, Family History, and Neurocognitive Test Cut Scores in Predicting ADHD and Non-ADHD Group Status

\begin{tabular}{|c|c|c|c|c|}
\hline Included information & $\boldsymbol{\beta}$ & $p$ & $O R(\mathrm{Cl})$ & $\begin{array}{l}\text { Classification accuracy (non-ADHD, } \\
\text { ADHD) }\end{array}$ \\
\hline \multicolumn{5}{|l|}{ Step 1: self-report current behavior } \\
\hline Current ADHD symptom score & .16 & $<.001$ & $1.2[1.1,1.3]$ & \\
\hline Current BDI score & -.06 & .008 & $.94[.90, .98]$ & $77.4(76.4,78.6)$ \\
\hline \multicolumn{5}{|l|}{$\begin{array}{l}\text { Step 2: self-report childhood } \\
\text { behavior }\end{array}$} \\
\hline Childhood inattention symptoms & .12 & .009 & $\begin{array}{l}1.12[1.03, \\
1.21]\end{array}$ & $80.9(80.3,81.6)$ \\
\hline \multicolumn{5}{|l|}{$\begin{array}{l}\text { Step 3: informant report current } \\
\text { behavior }\end{array}$} \\
\hline Informant ADHD symptom score & .19 & $<.001$ & $\begin{array}{l}1.21[1.15 \\
1.27]\end{array}$ & $82.6(81.9,83.5)$ \\
\hline \multicolumn{5}{|l|}{ Step 4: family history of ADHD } \\
\hline $\begin{array}{l}\text { First degree family member with } \\
\text { ADHD }\end{array}$ & 1.24 & .033 & $3.5[1.5,7.8]$ & $85.2(81.9,89.3)$ \\
\hline \multicolumn{5}{|l|}{$\begin{array}{l}\text { Step 5: neurocognitive test cut } \\
\text { scores }\end{array}$} \\
\hline TOVA reaction time variability & 1.14 & .023 & $3.1[1.1,8.9]$ & $87.4(86.6,88.3)$ \\
\hline
\end{tabular}

Note. ADHD_attention-deficit/hyperactivity disorder; BDI = Beck Depression Inventory; TOVA = Test of Variables of Attention. 


\section{Discussion}

The current study examined multiple neuropsychological test measures in conjunction with self- and informant ratings of current and childhood ADHD symptoms in order to ascertain the extent to which inclusion of these behavioral measures might improve the diagnostic accuracy of adult ADHD assessment. The current work sought to extend past research in this area by examining a large battery of neuropsychological test measures as well as several PVTs and SVTs, among a diverse sample of adults with ADHD as well as nondisordered controls and adults with depression.

There are four sets of notable findings stemming from this work. First, our analyses found that a combined approach that utilized self and informant ADHD symptom ratings, family history of ADHD, and neuropsychological test measures yielded a classification accuracy of approximately $87 \%$ when distinguishing participants with and without ADHD. Similar to past work, our findings support including retrospective ratings of childhood symptoms, particularly inattention (Kooij et al., 2010), along with informant ratings of behavior in the diagnostic assessment of ADHD (Sibley et al., 2017). Additionally, inclusion of ADHD family history, which is sometimes (although not always) gathered as part of an unstructured interview, significantly increased the classification accuracy. This suggests that it may be advantageous to gather this information in research and clinical assessment of ADHD, even if that information is not formally part of the diagnostic criteria.

Second, our findings regarding the role of neuropsychological test measures in the diagnostic assessment of ADHD were mixed. ROC analyses as well as linear and logistic regression analyses identified a subset of measures that each uniquely added to the discrimination between ADHD and non-ADHD adults. These measures included indices of working memory, inhibition, response speed and variability, and sustained attention, all domains which largely correspond to the largest group-difference effect sizes in the ADHD neurocognitive literature (Willcutt, Doyle, Nigg, Faraone, \& Pennington, 2005). Notably, three of these six measures were from the TOVA, suggesting that indices of response speed, response variability, and sustained attention may be particularly important for identifying adult ADHD. However, the TOVA may have also emerged as a salient predictor of diagnostic group due to its superior measurement precision (e.g., RTs and accuracy of performance are measured via computer and calculated in milliseconds), which may increase the sensitivity of this test for identifying deficits in sustained attention.

Furthermore, similar to much of the past work in this area, each single neuropsychological test measure poorly discriminated individuals with and without ADHD, based on the ROC analyses. In fact, several measures commonly used in clinical practice (i.e., the PASAT, NAB Numbers and Letters) were no better than chance at distinguishing individuals with and without ADHD (i.e., controls and depressed participants) Thus, inclusion of a long and extensive neuropsychological testing battery does not appear to yield much in terms of improving the diagnostic accuracy of adult ADHD assessment.

Third, additional analyses of these neuropsychological test measures that aimed to maximize the sensitivity and specificity of their prediction of ADHD diagnostic status revealed cut scores that were largely in the average range relative to the norms developed for each measure. This may be due, in part, to the overall higher levels of educational attainment and intellectual functioning in this sample. Some prior work has suggested that higher intellectual functioning may potentially "mask" executive functioning deficits in particular among adults with ADHD (Milioni et al., 2017). Further, these findings are in line with past work, which has suggested that adults with ADHD may exhibit less severe neuropsychological impairment (Salomone, Fleming, Bramham, O'Connell, \& Robertson, 2016), but may instead show more heterogeneity in terms of degree and types of cognitive deficits (Mostert et al., 2018). Regardless, this set of findings may be particularly relevant in the assessment of ADHD among college students. That is, adults with above average global cognitive abilities may underperform on some of these tasks relative to their IQ, even though their performance may be within an average range when compared with a broader population of adults. (Weyandt et al., 2013). 
Further, our findings of average-range cut scores that discriminated ADHD and non-ADHD participants within our sample may also explain findings from prior work regarding the lack of utility of neuropsychological tests in diagnosing adult ADHD. That is, neuropsychological tests may not have appeared to be useful for diagnosis in some prior work if an individual had to score substantially below the included norms (rather than low relative to a comparison or peer group) to be deemed impaired on a particular measure. While this may not account for all of the mixed findings in past research regarding the utility of neuropsychological tests in diagnosing adult ADHD, our findings strongly suggest that the criteria used to identify impairment on any neuropsychological tests be considered carefully and in relation to the individual's appropriate reference group (e.g., college-educated adults, high-average intellectual functioning). Future work may benefit by developing college-level norms for some measures commonly used in neuropsychological research and in evaluations of young adults with ADHD (Weyandt et al., 2013).

Fourth, our findings did not reveal many problems with invalid symptom presentation based on the results of PVTs and a symptom validity measure. Only $2 \%$ of the participants in this study were identified as making an invalid symptom presentation (i.e., below thresholds on 2 or more PVTs/SVTs). This is a substantially lower percentage than those found in studies of young adult patients presenting for ADHD assessment in clinical settings. Based on the conservative Slick, Sherman, and Iverson (1999) malingering criteria, prior work has estimated that 27\% (Marshall et al., 2016), 22\% (Marshall, et al., 2010), and 10\% (Pella, Hill, Shelton, Elliott, \& Gouvier, 2012) of college students made a suspect effort in their cognitive assessments. However, the participants in the current study had already been diagnosed with ADHD and their retaining this diagnosis was not in question. Therefore, it is highly likely that the participants in our study did not have the same set of incentives or motivations for making an invalid symptom presentation. Unfortunately, this unusually small percentage of individuals making an invalid symptom presentation prevented this study from producing meaningful data concerning the incremental predictive validity of including validity measures in an ADHD assessment battery. Nevertheless, prior work and clinical practice guidelines have strongly supported the need for such PVTs in order to identify invalid symptom presentation in this group, which may obscure clinical assessment and diagnosis of adults with ADHD (Bush et al., 2005; Heilbronner et al., 2009; Marshall et al., 2016; Tucha, Fuermaier, Koerts, Groen, \& Thome, 2015).

Overall, our findings supported including the following measures in a diagnostic assessment of ADHD (in addition to the clinical interview): (a) self-reports of ADHD, functional impairment, and potential comorbid problems, including depression; (b) retrospective reports of childhood ADHD symptoms; (c) informant reports of symptoms; (d) any positive family history of ADHD diagnoses; (e) performance and symptom validity measures; and (f) the TOVA or similar computerized continuous performance task. While our findings only offer some support for inclusion of neuropsychological tests in the diagnostic assessment of adult ADHD, more work is needed to determine if such tests significantly benefit diagnostic decision making in situations in which the results of other means of assessment (i.e., rating scales, clinical interview) are equivocal. Additionally, while these neuropsychological measures may slightly increase diagnostic accuracy, assessments of neurocognitive functioning, via testing or behavior ratings (e.g., the BDEFS), may be beneficial for understanding impairment and treatment targets in studies of intervention (Kooij et al., 2010; Solanto et al., 2010). Further, recent work focusing on neuropsychological test performance among adults with ADHD has demonstrated significant heterogeneity in performance across individuals (van Lieshout et al., 2013), some of which does not appear to be connected to the persistence or remittance of ADHD symptoms. Indeed, recent controversial work has even suggested that adult-onset ADHD may be a separate syndrome and associated with disparate risk factors and outcomes (Moffitt et al., 2015), although this possibility has also been questioned (Agnew-Blais et al., 2016).

There are several limitations to the current work. First, while our battery was comprehensive, some potentially ADHD-related behavioral problem domains may not have been properly covered in our measures. Measures of reward responsivity (von Rhein et al., 2015; Wetterling et al., 2015), emotional dysregulation (Barkley, 2015), and temporal discounting (Jackson \& MacKillop, 2016), in particular, may provide additional utility in 
distinguishing adults with and without ADHD. Second, the limited precision of cognitive processing speed measurement on some tasks may have limited their utility. Future work may benefit by incorporating computerized measures of several of these tasks to determine if improvement in cognitive processing speed measurement precision may enhance their usefulness in clinical assessment. For example, computerized working memory tests that include speed and accuracy measures might significantly increase the sensitivity of these tests to ADHD-related deficits (Alderson et al., 2013).

This work was also limited by considering only one clinical comparison group (e.g., depression). Examination of the degree to which these measures may distinguish among those with ADHD and other common comorbidities in adulthood, particularly anxiety disorders, as well as the impact of comorbid ADHD and internalizing symptoms on multiple domains of cognitive functioning, will be essential to future research in this area. We also excluded many individuals with comorbid neurodevelopmental problems (e.g., learning disorders). While there is evidence of shared deficits among individuals with ADHD and learning disorders, and enhanced deficits among those with comorbid profiles, we elected to exclude individuals with learning disorders in the current study. This decision may have then actually contributed to an underestimation of group differences observed, given that these excluded individuals with comorbid profiles may have performed equally poor or worse on our test battery relative to those with ADHD alone. Additionally, the relative smaller size of the depressed group may limit the generalizability of our findings regarding distinctions (or lack thereof) in cognitive performance among adults with ADHD and those with depressive disorders.

Future work would also benefit by examining neuropsychological tests and symptom validity measures as predictors of ADHD diagnosis in particular cases in which traditional clinical interviews and rating scales have produced equivocal findings. That is, some of these measures may not have considerable utility in distinguishing those individuals at the extreme end of the symptomatology distributions (i.e., those with severe ADHD symptoms, those with no ADHD symptoms). However, they may be more useful in distinguishing among those in the middle portion of the symptom severity distribution, particularly given the arbitrary nature of diagnostic cut points. That is, the utility of neuropsychological tests in identifying ADHD may indeed vary as a function of symptom severity.

Lastly, our sample was limited to volunteer research participants who were predominately Caucasian and who had completed a college degree. These three factors (self-selection, ethnic homogeneity, higher education level) may limit the generalizability of our findings. It is also important to note that we implemented multiple measures of symptom and performance validity into our battery, in line with current concerns regarding adults feigning ADHD (see the December 2017 issue of Psychological Assessment including Fuermaier et al., 2017; Walls, Wallace, Brothers, \& Berry, 2017). However, our ADHD participants had already been diagnosed previously, which may be one reason that our validity measures revealed few participants with questionable performance. Even so, examination of symptom and performance validity remains of paramount concern in assessment of adult ADHD.

Overall, findings from the current study indicated that neuropsychological testing added incrementally in predicting ADHD diagnoses among young adults. However, effects were small and the utility of individual tests was modest in the absence of other assessment information. A diagnostic protocol that included self- and informant ratings of current and childhood symptoms, family history of ADHD, and performance on a continuous performance test had high classification accuracy and appeared to be the most efficient in diagnosing ADHD among adults. Future work should incorporate performance and validity assessments as well as determine the utility of this battery in predicting ADHD diagnosis and related impairments across the spectrum of ADHD symptom severity. 


\section{References}

Advokat, C., Lane, S. M., \& Luo, C. (2011). College students with and without ADHD: Comparison of self-report of medication usage, study habits, and academic achievement. Journal of Attention Disorders, 15, 656-666. $10.1177 / 1087054710371168$

Agnew-Blais, J. C., Polanczyk, G. V., Danese, A., Wertz, J., Moffitt, T. E., \& Arseneault, L. (2016). Evaluation of the persistence, remission, and emergence of attention-deficit/hyperactivity disorder in young adulthood. Journal of the American Medical Association Psychiatry, 73, 713-720. 10.1001/jamapsychiatry.2016.0465

Alderson, R. M., Kasper, L. J., Hudec, K. L., \& Patros, C. H. G. (2013). Attention-deficit/hyperactivity disorder (ADHD) and working memory in adults: A meta-analytic review. Neuropsychology, 27, 287-302. 10.1037/a0032371

American Psychiatric Association. (2013). Diagnostic and statistical manual of mental disorders (5th ed.). Arlington, VA: Author.

Arria, A. M., Caldeira, K. M., O’Grady, K. E., Vincent, K. B., Johnson, E. P., \& Wish, E. D. (2008). Nonmedical use of prescription stimulants among college students: associations with attention-deficit-hyperactivity disorder and polydrug use. Pharmacotherapy, 28, 156-169. 10.1592/phco.28.2.156

Babikian, T., Boone, K. B., Lu, P., \& Arnold, G. (2006). Sensitivity and specificity of various digit span scores in the detection of suspect effort. The Clinical Neuropsychologist, 20, 145-159. 10.1080/13854040590947362

Barkley, R. A. (2011a). Barkley Adult ADHD Rating Scale (BAARS-IV). New York, NY: Guilford Press.

Barkley, R. A. (2011b). Barkley Deficits in Executive Function Scale (BDEFS). New York, NY: Guilford Press.

Barkley, R. A. (2011c). Barkley Functional Impairment Scale (BFIS). New York, NY: Guilford Press.

Barkley, R. (2015). Emotional dysregulation is a core component of ADHD. In R.Barkley (Ed.), Attention-deficit hyperactivity disorder: A handbook for diagnosis and treatment (4th ed., pp. 81-115). New York, NY: Guilford Press.

Barkley, R. A., Murphy, K. R., \& Fischer, M. (2008). ADHD in Adults: What the Science Says. New York, NY: The Guilford Press.

Beck, A. T., \& Steer, R. A. (1993). Beck Anxiety Inventory manual. San Antonio, TX: Psychological Corporation.

Beck, A. T., Steer, R. A., \& Brown, G. K. (1996). Manual for the Beck Depression Inventory-II. San Antonio, TX: Psychological Corporation.

Bell, A. S. (2011). A critical review of ADHD diagnostic criteria: What to address in the DSM-V. Journal of Attention Disorders, 15, 3-10. 10.1177/1087054710365982

Bledsoe, J. C., Xiao, D., Chaovalitwongse, A., Mehta, S., Grabowski, T. J., Semrud-Clikeman, M., . . Breiger, D. (2016). Diagnostic classification of ADHD versus control. Journal of Attention Disorders. Advance online publication. 10.1177/1087054716649666

Boone, K. B. (2009). The need for continuous and comprehensive sampling of effort/response bias during neuropsychological examinations. The Clinical Neuropsychologist, 23, 729-741. $10.1080 / 13854040802427803$

Boone, K., Lu, P., \& Herzberg, D. (2002a). The b-test. Los Angeles, CA: Western Psychological Services.

Boone, K., Lu, P., \& Herzberg, D. (2002b). The Dot Counting Test. Los Angeles, CA: Western Psychological Services.

Boonstra, A. M., Oosterlaan, J., Sergeant, J. A., \& Buitelaar, J. K. (2005). Executive functioning in adult ADHD: A meta-analytic review. Psychological Medicine, 35, 1097-1108.

Bracken, B., \& Boatwright, B. (2005). CAT-A. Clinical Assessment of Attention Deficit-Adult professional manual. Lutz, FL: Psychological Assessment Resources.

Bush, S. S., Ruff, R. M., Tröster, A. I., Barth, J. T., Koffler, S. P., Pliskin, N. H., . . Silver, C. H. (2005). Symptom validity assessment: Practice issues and medical necessity NAN policy \& planning committee. Archives of Clinical Neuropsychology, 20, 419-426. 10.1016/j.acn.2005.02.002

Delis, D., Kaplan, E., \& Kramer, J. H. (2001). Delis-Kaplan executive function system. San Antonio, TX: The Psychological Corporation. 
Delis, D., Kramer, J. H., Kaplan, E., \& Ober, B. A. (2000). California Verbal Learning Test (2nd ed.). San Antonio, TX: The Psychological Corporation, Harcourt Assessment Company.

Diehr, M. C., Cherner, M., Wolfson, T. J., Miller, S. W., Grant, I., Heaton, R. K., \& the HIV Neurobehavioral Research Center. (2003). The 50- and 100-item short forms of the Paced Auditory Serial Addition Task (PASAT): Demographically corrected norms and comparisons with the full PASAT in normal and clinical samples. Journal of Clinical and Experimental Neuropsychology, 25, 571-585. 10.1076/jcen.25.4.571.13876

Doyle, A. E., Biederman, J., Seidman, L. J., Weber, W., \& Faraone, S. V. (2000). Diagnostic efficiency of neuropsychological test scores for discriminating boys with and without attention deficit-hyperactivity disorder. Journal of Consulting and Clinical Psychology, 68, 477-488. 10.1037/0022-006X.68.3.477

Drake, M. B., Riccio, C. A., \& Hale, N. S. (2017). Assessment of adult ADHD with college students. Journal of Attention Disorders, Advance online publication. 10.1177/1087054717698222

DuPaul, G. J., Weyandt, L. L., O'Dell, S. M., \& Varejao, M. (2009). College students with ADHD: Current status and future directions. Journal of Attention Disorders, 13, 234-250. 10.1177/1087054709340650

Dvorsky, M. R., Langberg, J. M., Molitor, S. J., \& Bourchtein, E. (2016). Clinical utility and predictive validity of parent and college student symptom ratings in predicting an ADHD diagnosis. Journal of Clinical Psychology, 72, 401-418. 10.1002/jclp.22268

Epstein, J. N., Kelleher, K. J., Baum, R., Brinkman, W. B., Peugh, J., Gardner, W., . . Langberg, J. (2014). Variability in ADHD care in community-based pediatrics. Pediatrics, 134, 1136-1143. 10.1542/peds.2014-1500

Fair, D. A., Bathula, D., Nikolas, M. A., \& Nigg, J. T. (2012). Distinct neuropsychological subgroups in typically developing youth inform heterogeneity in children with ADHD. Proceedings of the National Academy of Sciences of the United States of America, 109, 6769-6774. 10.1073/pnas.1115365109

Frazier, T. W., Demaree, H. A., \& Youngstrom, E. A. (2004). Meta-analysis of intellectual and neuropsychological test performance in attention-deficit/hyperactivity disorder. Neuropsychology, 18, 543-555. 10.1037/0894-4105.18.3.543

Fuermaier, A. B. M., Tucha, O., Koerts, J., Lange, K. W., Weisbrod, M., Aschenbrenner, S., \& Tucha, L. (2017). Noncredible cognitive performance at clinical evaluation of adult ADHD: An embedded validity indicator in a visuospatial working memory test. Psychological Assessment, 29, 1466-1479. 10.1037/pas0000534

Green, P. (2003). The Word Memory Test. Seattle, WA: Green's.

Greenberg, L., Kindschi, C., Dupuy, T., \& Corman, C. (1996). Test of Variables of Attention. Los Alamitos, CA: Universal Attention Disorders.

Grodzinsky, G. M., \& Barkley, R. A. (1999). Predictive power of frontal lobe tests in the diagnosis of attention deficit hyperactivity disorder. Clinical Neuropsychologist, 13, 12-21. 10.1076/clin.13.1.12.1983

Heilbronner, R. L., Sweet, J. J., Morgan, J. E., Larrabee, G. J., \& Millis, S. R., \& Conference Participants. (2009). American Academy of Clinical Neuropsychology Consensus Conference Statement on the neuropsychological assessment of effort, response bias, and malingering. The Clinical Neuropsychologist, 23, 1093-1129. 10.1080/13854040903155063

Hervey, A. S., Epstein, J. N., \& Curry, J. F. (2004). Neuropsychology of adults with attention-deficit/hyperactivity disorder: A meta-analytic review. Neuropsychology, 18, 485-503. 10.1037/0894-4105.18.3.485

Hinshaw, S. P., \& Sheffler, R. M. (2014). The ADHD explosion: Myths, medication, money and today's push for performance. New York, NY: Oxford University Press.

Jackson, J. N. S., \& MacKillop, J. (2016). Attention-deficit/hyperactivity disorder and monetary delay discounting: A meta-analysis of case-control studies. Biological Psychiatry: Cognitive Neuroscience and Neuroimaging, 1, 316-325.

Johansen, M. E., Matic, K., \& McAlearney, A. S. (2015). Attention deficit hyperactivity disorder medication use among teens and young adults. Journal of Adolescent Health, 57, 192-197. 10.1016/j.jadohealth.2015.04.009

Kessler, R. C., Adler, L., Barkley, R., Biederman, J., Conners, C. K., Demler, O., . . Zaslavsky, A. M. (2006). The prevalence and correlates of adult ADHD in the United States: Results from the National Comorbidity Survey Replication. The American Journal of Psychiatry, 163, 716-723. 10.1176/ajp.2006.163.4.716 
Kessler, R. C., Adler, L. A., Barkley, R., Biederman, J., Conners, C. K., Faraone, S. V., . . Zaslavsky, A. M. (2005). Patterns and predictors of attention-deficit/hyperactivity disorder persistence into adulthood: Results from the national comorbidity survey replication. Biological Psychiatry, 57, 1442-1451. 10.1016/j.biopsych.2005.04.001

Kessler, R. C., Green, J. G., Adler, L. A., Barkley, R. A., Chatterji, S., Faraone, S. V., . . Van Brunt, D. L. (2010). Structure and diagnosis of adult attention-deficit/hyperactivity disorder: Analysis of expanded symptom criteria from the Adult ADHD Clinical Diagnostic Scale. Archives of General Psychiatry, 67, 1168-1178. 10.1001/archgenpsychiatry.2010.146

Kieling, C., Kieling, R. R., Rohde, L. A., Frick, P. J., Moffitt, T., Nigg, J. T., . . Castellanos, F. X. (2010). The age at onset of attention deficit hyperactivity disorder. The American Journal of Psychiatry, 167, 14-16. 10.1176/appi.ajp.2009.09060796

Kooij, S. J. J., Bejerot, S., Blackwell, A., Caci, H., Casas-Brugué, M., Carpentier, P. J., . . Asherson, P. (2010). European consensus statement on diagnosis and treatment of adult ADHD: The European Network Adult ADHD. BMC Psychiatry, 10, 67. 10.1186/1471-244X-10-67

Lovejoy, D. W., Ball, J. D., Keats, M., Stutts, M. L., Spain, E. H., Janda, L., \& Janusz, J. (1999). Neuropsychological performance of adults with attention deficit hyperactivity disorder (ADHD): Diagnostic classification estimates for measures of frontal lobe/executive functioning. Journal of the International Neuropsychological Society, 5, 222-233. 10.1017/S1355617799533055

Mannuzza, S., Klein, R. G., Klein, D. F., Bessler, A., \& Shrout, P. (2002). Accuracy of adult recall of childhood attention deficit hyperactivity disorder. The American Journal of Psychiatry, 159, 1882-1888. 10.1176/appi.ajp.159.11.1882

Marshall, P. S., Hoelzle, J. B., Heyerdahl, D., \& Nelson, N. W. (2016). The impact of failing to identify suspect effort in patients undergoing adult attention-deficit/hyperactivity disorder (ADHD) assessment. Psychological Assessment, 28, 1290-1302. 10.1037/pas0000247

Marshall, P., Schroeder, R., O’Brien, J., Fischer, R., Ries, A., Blesi, B., \& Barker, J. (2010). Effectiveness of symptom validity measures in identifying cognitive and behavioral symptom exaggeration in adult attention deficit hyperactivity disorder. The Clinical Neuropsychologist, 24, 1204-1237. 10.1080/13854046.2010.514290

Matte, B., Anselmi, L., Salum, G. A., Kieling, C., Gonçalves, H., Menezes, A., . . Rohde, L. A. (2015). ADHD in DSM5: A field trial in a large, representative sample of 18- to 19-year-old adults. Psychological Medicine, 45, 361-373. 10.1017/S0033291714001470

Milioni, A. L. V., Chaim, T. M., Cavallet, M., de Oliveira, N. M., Annes, M., Dos Santos, B., .. Cunha, P. J. (2017). High IQ may "mask" the diagnosis of ADHD by compensating for deficits in executive functions in treatment-naïve adults with ADHD. Journal of Attention Disorders, 21, 455-464. $10.1177 / 1087054714554933$

Moffitt, T. E., Houts, R., Asherson, P., Belsky, D. W., Corcoran, D. L., Hammerle, M., . .Caspi, A. (2015). Is adult ADHD a childhood-onset neurodevelopmental disorder? Evidence from a four-decade longitudinal cohort study. The American Journal of Psychiatry, 172, 967-977. 10.1176/appi.ajp.2015.14101266

Mostert, J. C., Hoogman, M., Onnink, A. M. H., van Rooij, D., von Rhein, D., van Hulzen, K. J. E., . . .Franke, B. (2018). Similar subgroups based on cognitive performance parse heterogeneity in adults with ADHD and healthy controls. Journal of Attention Disorders, 22, 281-292. 10.1177/1087054715602332

Mostert, J. C., Onnink, A. M. H., Klein, M., Dammers, J., Harneit, A., Schulten, T., .. .Hoogman, M. (2015). Cognitive heterogeneity in adult attention deficit/hyperactivity disorder: A systematic analysis of neuropsychological measurements. European Neuropsychopharmacology, 25, 2062-2074. 10.1016/j.euroneuro.2015.08.010

Musso, M. W., \& Gouvier, W. D. (2014). "Why is this so hard?" A review of detection of malingered ADHD in college students. Journal of Attention Disorders, 18, 186-201. 10.1177/1087054712441970

Nelson, J. M., Whipple, B., Lindstrom, W., \& Foels, P. A. (2014). How is ADHD assessed and documented? Examination of psychological reports submitted to determine eligibility for postsecondary disability. Journal of Attention Disorders. Advance online publication. 10.1177/1087054714561860 
Nikolas, M. A., \& Burt, S. A. (2010). Genetic and environmental influences on ADHD symptom dimensions of inattention and hyperactivity: A meta-analysis. Journal of Abnormal Psychology, 119, 1-17. 10.1037/a0018010

Paris, J., Bhat, V., \& Thombs, B. (2015). Is adult attention-deficit hyperactivity disorder being overdiagnosed?The Canadian Journal of Psychiatry/La Revue canadienne de psychiatrie, 60, 324-328. 10.1177/070674371506000705

Pella, R. D., Hill, B. D., Shelton, J. T., Elliott, E., \& Gouvier, W. D. (2012). Evaluation of embedded malingering indices in a non-litigating clinical sample using control, clinical, and derived groups. Archives of Clinical Neuropsychology, 27, 45-57. 10.1093/arclin/acr090

Perugini, E. M., Harvey, E. A., Lovejoy, D. W., Sandstrom, K., \& Webb, A. H. (2000). The predictive power of combined neuropsychological measures for attention-deficit/hyperactivity disorder in children. Child Neuropsychology, 6, 101-114. 10.1076/chin.6.2.101.7059

Prevatt, F., Dehili, V., Taylor, N., \& Marshall, D. (2015). Anxiety in college students with ADHD: Relationship to cognitive functioning. Journal of Attention Disorders, 19, 222-230. 10.1177/1087054712457037

Ramsey, J. (2015). Psychological assessment of adults with ADHD. In R.Barkley (Ed.), Attention-deficit hyperactivity disorder-A handbook for diagnosis and treatment (4th ed., pp. 475-500). New York, NY: Guilford Press.

Rapport, L. J., Van Voorhis, A., Tzelepis, A., \& Friedman, S. R. (2001). Executive functioning in adult attentiondeficit hyperactivity disorder. The Clinical Neuropsychologist, 15, 479-491. 10.1076/clin.15.4.479.1878

Renoux, C., Shin, J.-Y., Dell'Aniello, S., Fergusson, E., \& Suissa, S. (2016). Prescribing trends of attention-deficit hyperactivity disorder (ADHD) medications in U. K. primary care, 1995-2015. British Journal of Clinical Pharmacology, 82, 858-868. 10.1111/bcp.13000

Root, J. C., Robbins, R. N., Chang, L., \& Van Gorp, W. G. (2006). Detection of inadequate effort on the California Verbal Learning Test-2nd ed.: Forced choice recognition and critical item analysis. Journal of the International Neuropsychological Society, 12, 688-696. 10.1017/S1355617706060838

Salomone, S., Fleming, G. R., Bramham, J., O'Connell, R. G., \& Robertson, I. H. (2016). Neuropsychological deficits in adult ADHD: Evidence for differential attentional impairments, deficient executive functions, and high self-reported functional impairments. Journal of Attention Disorders. Advance online publication. $10.1177 / 1087054715623045$

Salthouse, T. (1994). The aging of working memory. Neuropsychology, 8, 535-543. 10.1037/0894-4105.8.4.535

Schroeder, R. W., \& Marshall, P. S. (2010). Validation of the sentence repetition test as a measure of suspect effort. The Clinical Neuropsychologist, 24, 326-343. 10.1080/13854040903369441

Sibley, M. H., Coxe, S., \& Molina, B. S. G. (2017). Refining diagnostic procedures for adults with symptoms of ADHD. Assessment, 24, 290-296. 10.1177/1073191116676890

Slick, D. J., Sherman, E. M., \& Iverson, G. L. (1999). Diagnostic criteria for malingered neurocognitive dysfunction: proposed standards for clinical practice and research. The Clinical Neuropsychologist, 13, 545-561. 10.1076/1385-4046(199911)13:04;1-Y;FT545

Solanto, M. V., Marks, D. J., Wasserstein, J., Mitchell, K., Abikoff, H., Alvir, J. M. J., \& Kofman, M. D. (2010). Efficacy of meta-cognitive therapy for adult ADHD. The American Journal of Psychiatry, 167, 958-968. 10.1176/appi.ajp.2009.09081123

Spencer, T. J., Biederman, J., \& Mick, E. (2007). Attention-deficit/hyperactivity disorder: Diagnosis, lifespan, comorbidities, and neurobiology. Journal of Pediatric Psychology, 32, 631-642. 10.1093/jpepsy/jsm005

Strauss, E., Sherman, E. M., \& Spreen, O. (2006). A compendium of neuropsychological tests: Administration, norms, and commentary. New York, NY: Oxford University Press.

Tucha, L., Fuermaier, A. B. M., Koerts, J., Groen, Y., \& Thome, J. (2015). Detection of feigned attention deficit hyperactivity disorder. Journal of Neural Transmission, 122(Suppl. 1), S123-134. 10.1007/s00702-0141274-3

van Lieshout, M., Luman, M., Buitelaar, J., Rommelse, N. N. J., \& Oosterlaan, J. (2013). Does neurocognitive functioning predict future or persistence of ADHD? A systematic review. Clinical Psychology Review, 33, 539-560. 10.1016/j.cpr.2013.02.003 
Visser, S. N., Danielson, M. L., Bitsko, R. H., Holbrook, J. R., Kogan, M. D., Ghandour, R. M., . . Blumberg, S. J. (2014). Trends in the parent-report of health care provider-diagnosed and medicated attentiondeficit/hyperactivity disorder: United States, 2003-2011. Journal of the American Academy of Child \& Adolescent Psychiatry, 53, 34-46.e2. 10.1016/j.jaac.2013.09.001

Vitola, E. S., Bau, C. H. D., Salum, G. A., Horta, B. L., Quevedo, L., Barros, F. C., . . Grevet, E. H. (2017). Exploring DSM-5 ADHD criteria beyond young adulthood: Phenomenology, psychometric properties and prevalence in a large three-decade birth cohort. Psychological Medicine, 47, 744-754. $10.1017 /$ S0033291716002853

von Rhein, D., Cools, R., Zwiers, M. P., van der Schaaf, M., Franke, B., Luman, M., . . Buitelaar, J. (2015). Increased neural responses to reward in adolescents and young adults with attentiondeficit/hyperactivity disorder and their unaffected siblings. Journal of the American Academy of Child \& Adolescent Psychiatry, 54, 394-402. 10.1016/j.jaac.2015.02.012

Walls, B. D., Wallace, E. R., Brothers, S. L., \& Berry, D. T. R. (2017). Utility of the Conners' Adult ADHD Rating Scale validity scales in identifying simulated attention-deficit hyperactivity disorder and random responding. Psychological Assessment, 29, 1437-1446. 10.1037/pas0000530

Wechsler, D. (2008a). Wechsler Adult Intelligence Scale (4th ed.). San Antonio, TX: The Psychological Corporation.

Wechsler, D. (2008b). Wechsler Memory Scale (4th ed.). San Antonio, TX: The Psychological Corporation.

Wetterling, F., McCarthy, H., Tozzi, L., Skokauskas, N., O'Doherty, J. P., Mulligan, A., . . Frodl, T. (2015). Impaired reward processing in the human prefrontal cortex distinguishes between persistent and remittent attention deficit hyperactivity disorder. Human Brain Mapping, 36, 4648-4663. 10.1002/hbm.22944

Weyandt, L., DuPaul, G. J., Verdi, G., Rossi, J. S., Swentosky, A. J., Vilardo, B. S., . . Carson, K. (2013). The performance of college students with and without ADHD: Neuropsychological, academic, and psychosocial functioning. Journal of Psychopathology and Behavioral Assessment, 35, 421-435.

Weyandt, L. L., Oster, D. R., Gudmundsdottir, B. G., DuPaul, G. J., \& Anastopoulos, A. D. (2017). Neuropsychological functioning in college students with and without ADHD. Neuropsychology, 31, 160172. $10.1037 /$ neu0000326

White, T., \& Stern, R. (2003). Neuropsychological Assessment Battery. Lutz, FL: Psychological Assessment Resources.

Willcutt, E. G., Doyle, A. E., Nigg, J. T., Faraone, S. V., \& Pennington, B. F. (2005). Validity of the executive function theory of attention-deficit/hyperactivity disorder: A meta-analytic review. Biological Psychiatry, 57, 1336-1346. 10.1016/j.biopsych.2005.02.006 